\title{
Prazer e sofrimento no trabalho das agentes de segurança penitenciária
}

\author{
Rubia Minuzzi Tschiedel \\ Superintendência dos Serviços Penitenciários \\ Janine Kieling Monteiro \\ Universidade do Vale do Rio dos Sinos
}

\begin{abstract}
Resumo
Com o intuito de conhecer o trabalho no sistema prisional gaúcho e as implicações deste na saúde mental das agentes de segurança penitenciária, realizou-se um estudo qualitativo com o objetivo de identificar os aspectos da organização do trabalho que produzem prazer e sofrimento no trabalho das agentes de segurança penitenciária e descrever as estratégias defensivas utilizadas por estas trabalhadoras no seu cotidiano laboral. Para a coleta de dados foi utilizada uma entrevista semiestruturada que reuniu oito participantes. Entre os resultados, os achados apontam que cumprir com obrigações, ter gratificação salarial e estabilidade no emprego como vivências de prazer, e a precariedade das condições de trabalho como elemento provocador de sofrimento. As estratégias defensivas que mais se evidenciaram foram a negação e a racionalização. Conclui-se que as profissionais estudadas tentam encontrar caminhos para a manutenção da saúde, ao utilizarem mecanismos que favorecem o enfrentamento do sofrimento e a busca do prazer.
\end{abstract}

Palavras-chave: saúde do trabalhador; psicodinâmica do trabalho; estratégias defensivas; agentes penitenciárias.

\begin{abstract}
Pleasure and suffering in the work of penitentiary officers. With the goal of know the work in the prison system gaucho and the implications of this on the mental health of penitentiary security officers, was performed one study qualitative with the goal was to identify the aspects in the work organization that produce pleasure and the ones that produce suffering in the penitentiary security officers and to describe the defensive strategies used by these workers in their daily labor routine. For such, a semi-structured interview has been used to gather the data that joined eight participants. The reports were treated using content analysis. Among the results, the findings indicate that comply with the obligations have bonus salary and job stability as experiences of pleasure experience, and the poor labor conditions as the element causing the suffering. The defensive strategies that were most apparent were the negation and rationalization. It is concluded that the professional who participated in this study tried to find ways to maintain their health, by using mechanisms that support the confrontation against the suffering and the pursuit of pleasure.
\end{abstract}

Keywords: occupational health; psychodynamics of work; defensive strategies; penitentiary officers.

\section{Resumen}

El placer y el sufrimiento en el trabajo de los agentes seguridad de la prisión. Con el objetivo de cumplir con el trabajo en el sistema penitenciario gaucho y las implicaciones de este en la salud mental de los guardias de la prisión, había un estudio cualitativo con el objetivo de identificar los aspectos de la organización del trabajo que producen placer y sufrimiento en el trabajo de los agentes seguridad de la prisión y describir las estrategias defensivas utilizadas por estos trabajadores en su trabajo diario. Para la recolección de datos se utilizó una entrevista semi-estructurada que reunió a ocho participantes. Entre los resultados, las conclusiones apuntan a cumplir con las obligaciones, tienen sueldos bono y la estabilidad laboral como experiencias de placer, y la precariedad de las condiciones de trabajo como elemento provocador de sufrimiento. Estrategias defensivas mostraron que la mayoría eran la negación y la racionalización. Llegamos a la conclusión de que los profesionales estudiados tratan de encontrar formas de mantener la salud, el uso de mecanismos que promuevan afrontar el sufrimiento y la búsqueda del placer.

Palabras clave: salud de los trabajadores; psicodinámica del trabajo; las estrategias defensivas; funcionarios de prisiones. 
$\mathrm{O}$ trabalho pode ser entendido através de um universo de significados (tais como: sacrifício, sobrevivência, realização, formador da identidade, status social) cujas transformações ocorridas no tempo e na história trouxeram implicações aos modos de viver dos trabalhadores (Grisci, 1999). Nesse contexto, o trabalho transita em território ambivalente, uma vez que tanto pode dar origem a processos de alienação e mesmo de descompensação psíquica como pode ser fonte de saúde e instrumento de emancipação. $O$ labor pressupõe não somente uma preocupação com a eficácia técnica, mas busca incorporar argumentos de proteção e de realização do ego, relativos ao viver em comum, ao mundo social. Assim, o trabalho não é somente a execução de atividades produtivas, mas também é espaço de convivência (Dejours, 1999).

A saúde do trabalhador é vivenciada nas relações de prazer e sofrimento no trabalho. O prazer é naturalmente edificante, enquanto o sofrimento desestabiliza. Para lidar com o sofrimento o sujeito desenvolve estratégias de defesa, que podem ser tanto coletivas quanto individuais. Pelo simples fato de o sofrimento ser inerente à condição existencial humana, ele sempre existirá, mas poderá ser amenizado, evitado ou ressignificado (Mendes, 1999; Mendes, 2007; Mendes, Borges, \& Ferreira, 2002). Vale ressaltar que sofrimento não é sinônimo de doença, assim como prazer não é sinônimo de saúde e o quanto é tênue e estreita a fronteira entre a vivência do prazer e do sofrimento (Almeida $\&$ Merlo, 2008).

Trabalhar no sistema penitenciário é usualmente retratado de forma depreciativa e pode-se classificar, por diversas razões, a classe de agente penitenciário como uma ocupação arriscada e estressante. Nos últimos anos foram feitas algumas pesquisas sobre a saúde física e psicológica dessa categoria (Correia, 2006; Fernandes et al., 2002; Kurowski \& Moreno-Jimenez, 2002; Vasconcelos, 2000). Nesse contexto, entender a influência da organização do trabalho na qualidade de vida, na saúde mental, no desgaste e no adoecimento dos trabalhadores é de fundamental importância, tanto para a compreensão quanto para a intervenção em situações de trabalho que podem levar a diversas formas de sofrimento, adoecimento e exclusão (Lancman \& Jardim, 2004).

A organização do trabalho e as implicações na saúde de agentes de segurança penitenciária constituem-se como objeto deste estudo. Esses trabalhadores desempenham a função de vigiar e reeducar indivíduos adultos, que são privados de sua liberdade, o que pode vir a tornar este grupo de trabalhadores suscetível ao sofrimento psíquico (Rumin, 2006). Para contemplar o objeto acima, será utilizada a abordagem da Psicodinâmica do Trabalho, que se dedica à análise das relações dinâmicas tecidas entre o sujeito e a organização do trabalho, valorizando os processos subjetivos e intersubjetivos mobilizados no trabalhar (Dejours, 2007).

O enfoque nas agentes de segurança penitenciária se deu em razão da invisibilidade atribuída a essa categoria, mesmo em um país aonde as dimensões da realidade carcerária vem aumentando vertiginosamente e as suas condições são precárias.

\section{Prazer e sofrimento no trabalho}

Considera-se que saúde no trabalho não implica ausência de sofrimento, mas possibilidades internas e externas do sujeito de transformação das situações adversas, no movimento de busca de prazer e fuga do sofrimento. O equilíbrio da saúde no trabalho é marcado pelas vivências de prazer e sofrimento, pela utilização de mecanismos capazes de mobilizar os trabalhadores em busca de uma relação mais gratificante no trabalho e pela dinâmica de reconhecimento, fator essencial no processo de construção da identidade do trabalhador (Mendes, 2004).

Nesse sentido, é de fundamental importância compreender as formas de organização social do trabalho e seus reflexos na qualidade de vida, bem como na saúde e na forma de adoecimento dos trabalhadores, para assim perceber que situações estão gerando sofrimento e agravos à saúde (Heloani \& Lancman, 2004). A organização do trabalho é uma relação social, é um acordo entre objetivos e prescrições (procedimentos, maneira de organizar o trabalho, método) e as dificuldades reais para a realização do trabalho. Na cultura do trabalho existem dois aspectos inseparáveis, o modo de ser e o modo de fazer, que contribuirão para se compreender as dimensões do trabalho prescrito e do trabalho real no contexto das organizações (Ferreira, 2004).

A centralidade do trabalho no mundo contemporâneo tem sido constantemente afirmada, sendo que o trabalho é parte fundamental na construção da saúde e da vida e estabelece uma relação com o real (Eccel, Grisci, \& Tonon, 2010). Nesse sentido, o sofrimento no trabalho é inevitável, pois coloca o sujeito na presença do inesperado, podendo gerar uma sensação de fracasso e incapacidade. É importante nessa dinâmica analisar quais são os destinos possíveis para o sofrimento, podendo este ser transformado em prazer e criatividade ou resultar em frustração e adoecimento (Dejours, 2007).

O trabalho pode ser fonte de prazer, ao possibilitar a aplicação da inteligência e, ainda, quando se reconhece a importância da mesma para a organização laboral. O trabalho, assim, é percebido como saúde, pois as relações do mesmo se tornam mediadoras das realizações do sujeito e da construção da sua identidade (Dejours, 2004). Quando a atividade do trabalhador é reconhecida e valorizada pela organização, o trabalho se torna estruturante na identidade do indivíduo. Mas quando esta mesma atividade não é significativa para o sujeito, para a organização nem para a sociedade, ela pode ser fonte de sofrimento (Dejours, 1992).

Uma das descobertas mais importantes realizadas pela teoria dejouriana foi a constatação de que os indivíduos desenvolvem estratégias de defesa individuais e coletivas, para fazer uso frente ao sofrimento e aos constrangimentos ligados ao trabalho. Segundo Dejours (1994), o sofrimento pode promover estratégias defensivas, suscitando assim uma ideologia defensiva, em que seu caráter é vital, fundamental e necessário. As estratégias coletivas de defesa podem surgir substituindo os mecanismos de defesa individuais, com o intuito de ressignificar algo que causa sofrimento e agindo sobre a percepção da realidade, tornando-a mais suave, concedendo ao sujeito uma segurança que, apenas com suas próprias defesas, ele seria incapaz de garantir.

Além de exercer um papel de proteção contra os afetos dolorosos vindo das adversidades do trabalho e estabelecendo uma forma específica de cooperação entre os trabalhadores, as estratégias defensivas podem operar como um sinal de alerta para 
a saúde psíquica dos sujeitos. A intensidade do uso das defesas pode levar ao seu fracasso, anestesiando o sofrimento vindo do ambiente laboral e, conseguintemente, levar ao adoecimento e à alienação (Barros \& Mendes, 2003). É nesse contexto que a clínica psicodinâmica pode apresentar sua contribuição como possibilidade de recriar uma nova organização de trabalho, novas normas do fazer e do viver junto. Para isso, é necessário conhecer, desconstruir e reconstruir o modo defensivo coletivo (Mendes \& Araújo, 2011).

Para Dejours (2010), a Psicodinâmica do Trabalho é uma disciplina clínica, que se apoia na descrição e no conhecimento das relações entre trabalho e saúde mental, trazendo a ideia de que é o sujeito que luta contra a loucura do trabalho, as patologias e a doença mental. A clínica do trabalho e da ação, proposta por Dejours, favorece o lugar da autonomia, criação e negociação: estruturação de estratégias saudáveis para mediar o sofrimento, ressignificá-lo e convertê-lo em vivência de prazer (Mendes \& Araújo, 2011). Desta forma, a fala do trabalhador é fundamental para compreendermos o prazer-sofrimento e a saúde do trabalhador (Mendes, 2007).

\section{O sistema prisional Brasileiro e do Rio Grande do Sul}

No Brasil, em 2003, havia 12.527 mulheres presas e no mesmo período havia 272.462 homens presos. Entre 1998 e 2003 houve um aumento de 6.069 presos no sistema, ou seja, um acréscimo de 48,01\% sobre o total do ano de 1998. Ao longo desse período, foram criadas 5.035 novas vagas que, em níveis mínimos, permitiram a manutenção da situação de superlotação (Ministério da Justiça, 2011).

No Rio Grande do Sul (RS), apenas no ano de 2002, a massa carcerária aumentou em 1.600 presos. Dessa forma, o crescimento populacional gaúcho tem sido maior atrás das grades do que na rua. De 2001 a 2003 a população prisional aumentou $24,8 \%$ enquanto a população em geral aumentou $1,9 \%$. Os números demonstram que a situação do sistema prisional gaúcho é cada vez mais preocupante. $\mathrm{O}$ aumento populacional carcerário desmedido, sem o equivalente aumento no número de vagas, pode ser observado até mesmo na população prisional feminina, duplicada em apenas dois anos (Rio Grande do Sul, 2006).

No RS, dados de 2007 apresentados pelo Sistema Integrado de Informações Penitenciárias (INFOPEN), informam que a população carcerária está composta de 24.694 homens e 879 mulheres. O resultado do crescimento da população prisional, não acompanhado pela criação de novas vagas, é a superlotação dos estabelecimentos e o aumento do déficit de vagas. Enquanto em 2003 o déficit de vagas era de 2.900 presos, em 2006 a população carcerária contabilizava um déficit de 7.562 vagas.

Em contrapartida, o número de pessoal encarregado das execuções penais não aumenta na mesma medida que aumenta a população atrás das grades. Para evitar rebeliões ou fugas, ou até mesmo para aliviar a superlotação nos presídios, uma das medidas tem sido as transferências. Essas últimas, sejam elas por superlotação ou a pedido dos presos ou forma de punição, já são uma realidade (Ministério da Justiça, 2011).

De acordo com o Departamento Penitenciário Nacional (DEPEN), em dezembro de 2006 os servidores penitenciários no Brasil compunham um quadro de 61.275 pessoas, dos quais 46.310 são agentes penitenciários ( $76 \%$ do total de funcionários). Ainda de acordo com o DEPEN, no Rio Grande do Sul existem 2.101 agentes penitenciários, totalizando 2.806 funcionários integrantes do sistema prisional. Sendo assim, os agentes penitenciários correspondem a 75\% dos servidores do sistema prisional do Estado.

Além de facilitarem o entendimento da dimensão do sistema prisional, os dados acima contribuem para que se perceba a importância de pesquisas nessa área, haja vista a quantidade de pessoas envolvidas. Essas trabalhadoras estão em contato direto com as apenadas e, portanto, estão mais suscetíveis à influência dos paradoxos (punir ou reeducar?) e das péssimas condições do sistema carcerário.

\section{Agentes de segurança penitenciária}

Os agentes da segurança penitenciária são aqueles que realizam serviços de vigilância, custódia e disciplina dos encarcerados e, para isso, o desenvolvimento dessas atividades é executado em determinadas condições de trabalho, que podem determinar riscos para a saúde física e/ou mental dos agentes (Kurowski \& Moreno-Jiménez, 2002). Existem agentes penitenciários masculinos e femininos, sendo que o gênero dos internos é que vai determinar a quantidade de agentes de cada sexo que vão atuar dentro de determinado presídio (Taets, 2009). O presente estudo realizou-se em um albergue feminino, sendo as participantes agentes penitenciárias do gênero feminino.

A denominação Agente de Segurança Penitenciária - ASP - cabe aos trabalhadores de segurança e disciplina das unidades penais e hospitalares, independentemente das funções que exercem ou dos postos em que trabalham. Como exigências para admissão ao cargo de ASP, segundo a Lei $n^{\circ} 9.228$, de 01/02/1991, o candidato deve ter entre 21 e 35 anos completos, ter concluído o ensino médio e submeter-se a concurso público. Nos documentos exigidos para inscrição na Escola de Formação, nota-se a preocupação com o passado jurídico e criminal dos aprovados (Vasconcelos, 2000).

Segundo a Superintendência dos Serviços Penitenciários (SUSEPE) (2006), na descrição sucinta das atribuições dos cargos, no que se refere aos agentes de segurança penitenciária, constam atividades como: cuidar da disciplina e segurança dos presos; fazer rondas periódicas; providenciar a assistência aos presos; informar as autoridades competentes sobre as ocorrências surgidas no seu período de trabalho; verificar as condições de segurança física do estabelecimento; verificar as condições de limpeza e higiene das celas; efetuar registros de suas atividades; fiscalizar a entrada e a saída de pessoas e veículos nos estabelecimentos penais, incluindo execução de serviços de revistas corporais; efetuar a conferência periódica da população carcerária. Sua jornada de trabalho constitui-se de 40 horas semanais em regime de plantões de $12 \mathrm{~h}$ por $24 \mathrm{~h}$ e de $12 \mathrm{~h}$ por $36 \mathrm{~h}$ (sucessivamente).

Pode-se classificar, por diversas razões, a categoria de agente penitenciário como uma ocupação arriscada e estressante. Esse trabalho pode levar a distúrbios de várias ordens, tanto físicos quanto psicológicos. O risco e a vulnerabilidade são inerentes às características de trabalho no cárcere (Lourenço, 2010). 
Nesse sentido, Correia (2006) aponta que a profissão do agente penitenciário, por sua natureza, requisita uma abordagem e um conjunto de medidas de proteção que garantam a integridade social, econômica e psicológica, inclusive através de formação continuada e diferenciação nas condições trabalhistas.

O estudo de Rumin (2006), com agentes penitenciários do estado de São Paulo, objetivou avaliar as condições de trabalho e os possíveis impactos sobre a saúde dos trabalhadores, e identificou que o reduzido número de servidores penitenciários tem levado estes a uma sobrecarga de trabalho. Os estudos com agentes penitenciários do Rio de Janeiro (Vasconcelos, 2000) e de Salvador (Fernandes et al, 2002) identificaram riscos biológicos desses trabalhadores serem contaminados por tuberculose e hepatite, em função das péssimas condições de trabalho. O estudo de Santos (2010), com agentes penitenciários do Rio Grande do Sul e do Rio Grande do Norte, constatou que outro fator de risco para os agentes penitenciários é o fenômeno da superlotação, pois esta última pode aumentar os riscos de ataques violentos entre os próprios encarcerados e entre os encarcerados e os agentes. Ainda nesse contexto, a violência, a corrupção, as doenças e a promiscuidade tendem a aumentar significativamente.

No cenário internacional, uma pesquisa realizada em 1997, apontou as 20 profissões mais estressantes, ficando em primeiro lugar a de oficial de prisão - no Rio Grande do Sul o termo é equivalente a agente penitenciário (Cooper, 1997).

Podemos observar que na atual conjuntura judiciária do país, não existe, na maioria dos casos, possibilidade para que o agente penitenciário exerça sua função com tranquilidade, pois existem presídios superlotados, causando assim más condições de trabalho, advertindo-se que, em muitos casos, apenas um agente penitenciário deve se desdobrar para realizar um trabalho que deveria ser dividido entre mais agentes, mas devido à falta de pessoal é distribuído de forma exacerbada, fazendo com que se exceda o nível de tarefas que cada um poderia exercer (Santos, 2010).

A questão da valorização profissional constitui uma das grandes frustrações dos agentes, devido à ausência de um plano de cargos e salários, que lhes permita uma mudança qualitativa por meio de promoções asseguradas legalmente (Vasconcelos, 2000). O estudo de Lourenço, (2010) indica que, na percepção dos agentes, as autoridades desconhecem o cotidiano prisional e não valorizam devidamente quem nele trabalha. Uma queixa rotineira, sobretudo de quem já está há mais tempo trabalhando no sistema prisional, é que os agentes nunca, ou quase nunca, são ouvidos sobre como a cadeia deveria funcionar, nem sobre o que deveria ser feito para que ela funcionasse melhor. Vivenciando de perto a cultura da prisão, os agentes afirmam poder conhecer melhor as chances de sucesso, a efetividade e a funcionalidade de certos procedimentos e propostas a serem adotados.

As características psicogênicas, ou seja, o risco de doenças causadas por transtornos psíquicos das cargas de trabalho (Laurrel \& Noriega, 1989) a que estão expostos os agentes de segurança penitenciária podem tornar este grupo de trabalhadores suscetível ao sofrimento psíquico. Os trabalhadores em geral possuem determinada carga de trabalho, esta carga diz respeito às exigências impostas pela carga de trabalho, podendo ela ser definida como quantitativa ou qualitativa. A qualitativa refere-se à dificuldade que o trabalho impõe em relação à capacidade do agente penitenciário de exercer suas funções. A quantitativa está ligada à quantidade de trabalho que o agente deve desempenhar, muitas vezes, neste caso, mais do que tem capacidade de suportar, isto pode acarretar em desgastes psicológicos, físicos e mentais (Rumin, 2006; Vasconcelos, 2000).

Centurião (1990, p. 47) afirma que o agente penitenciário, "está em íntimo contato com os detentos", e que tendo em vista as características de sua função, mesmo que quisesse, não poderia se afastar desses enquanto está em seu período de plantão. $\mathrm{O}$ mesmo é todo tempo "solicitado e procurado" pelos presos, e mesmo durante a noite, deve estar em vigilância permanente a fim de detectar qualquer alteração que possa acontecer, ou seja, o trabalho é contínuo e intenso. O agente, ao ingressar em um presídio mesmo que por turnos determinados, fica isolado de seu convívio social. O contato com familiares é restrito durante os turnos de trabalho e mesmo os telefonemas só podem ser feitos em caráter emergencial e por pouco tempo. Quando acontece algum incidente e o agente tem de permanecer com a escolta de um preso, nem sempre a hora de saída dos turnos é respeitada (Lourenço, 2010).

A saúde mental do agente penitenciário tem despertado preocupação, pois o presídio é um ambiente estressante onde ocorrem vários casos de afastamento do trabalho por decorrência de desgaste emocional ou de outros fatores relacionados (Rumin, 2006). Diante do exposto, destaca-se que o tema desta pesquisa possui relevância, pois trata da saúde do trabalhador e dos fatores que podem desencadear prejuízos psicossociais em funcionários que desempenham as funções de vigilância, custódia e disciplina dos apenados. Na análise das condições de trabalho desse grupo, foram identificados riscos de violência, precariedade nas condições de trabalho, riscos biológicos, entre outros. Soma-se a isso o escasso número de estudos sobre a categoria de agente de segurança penitenciária, em especial, com relação a agentes do gênero feminino.

Dessa forma, pretende-se no presente estudo identificar os aspectos da organização do trabalho que produzem prazer e os que produzem sofrimento no contexto laboral das agentes de segurança penitenciária e descrever as estratégias defensivas utilizadas por estas trabalhadoras no seu cotidiano laboral.

\section{Método}

Esta pesquisa utilizou a abordagem qualitativa com delineamento descritivo. No que se refere ao delineamento, Gil (1995) aponta que pesquisas de cunho descritivo têm por objetivo levantar as opiniões, atitudes e crenças de um grupo.

\section{Participantes}

Participaram do estudo oito agentes de segurança penitenciária do sexo feminino que desempenham suas atividades em um albergue feminino da região metropolitana de Porto Alegre/RS. Utilizou-se como critério de inclusão o fato de estar há pelo menos um ano trabalhando nesta função. Considerou-se o critério de saturação teórica, em que o fechamento amostral é operacionalmente definido como a suspensão de inclusão de novos participantes quando os dados obtidos passam a apresentar, 
na avaliação do pesquisador, certa redundância ou repetição, não sendo considerado relevante persistir na coleta de dados (Denzin $\&$ Lincoln, 1994). Na oitava entrevista, quando foi observado que não houve uma inclusão de conteúdo significativo com base no roteiro das entrevistas, optou-se por finalizar a coleta de dados.

\section{Instrumentos}

Foi elaborado um questionário sócio demográfico com objetivo de coletar informações para a caracterização das participantes e foi utilizada uma entrevista individual semiestruturada, que combinou perguntas fechadas com outras abertas, nas quais foi privilegiada a fala dos indivíduos expressa nessas ocasiões (Minayo, 1994). A entrevista teve questões referentes a temas previamente definidos: descrição do trabalho, aspectos que trazem satisfação e insatisfação no trabalho, estratégias para enfrentar o dia-a-dia de trabalho e sentimentos relacionados ao trabalho.

\section{Procedimentos de pesquisa}

Este trabalho foi submetido ao Comitê de Ética Em Pesquisa da Universidade do Vale do Rio dos Sinos e aprovado sob o número CEP 11/173. A pesquisa foi realizada conforme a Resolução 196/96 do Conselho Nacional de Saúde e a Resolução 016/2000 do Conselho Federal de Psicologia que regulamenta a pesquisa com seres humanos.

Primeiramente, foi feito contato com a direção da SUSEPE, onde foi solicitada cópia do projeto e, em seguida, houve a aprovação da pesquisa. Após isto, procurou-se a diretora do local para apresentar o projeto. Posteriormente, foi realizado um contato com as funcionárias da instituição. Em concordância, as participantes preencheram e assinaram o Termo de Consentimento Livre e Esclarecido (TCLE) para a autorização do estudo. As entrevistas foram gravadas e realizadas no mês de janeiro de 2012, com duração de aproximadamente 40 minutos, nas dependências do albergue feminino, sendo agendadas antecipadamente, mediante solicitação à diretora. Depois de realizadas as entrevistas, foram feitas as transcrições das mesmas para dar início à análise dos dados. Posteriormente, o material foi submetido a uma análise de conteúdo a priori, conforme os objetivos do estudo (Bardin, 1994).

\section{Resultados e discussão}

A partir dos objetivos elencados, ou seja, identificar os aspectos da organização do trabalho que produzem prazer e os que produzem sofrimento no trabalho das agentes de segurança penitenciária e descrever as estratégias defensivas utilizadas, partiu-se para a análise de conteúdo dos relatos das entrevistas com categorias a priori, as quais se subdividiram em subcategorias (Tabela 1).

Destaca-se, primeiramente, que o trabalho pode ser entendido como um aspecto fundamental para a vida das pessoas e constituir-se em um dos pilares para a estabilidade da família e da sociedade (Flach, Grisci, Silva, \& Manfredini, 2009). O trabalho não é lugar só do sofrimento ou só do prazer, mas é proveniente da dinâmica interna das situações e da organização do trabalho, ou seja, é produto desta dinâmica, das relações
Tabela 1

Categorias e Subcategorias Analisadas

\begin{tabular}{ll}
\hline \multicolumn{1}{c}{ Categorias } & \multicolumn{1}{c}{ Subcategorias } \\
\hline \multirow{3}{*}{ Prazer no trabalho } & Gostar do que faz \\
& Salário \\
& Escala de serviço \\
& Execução da revista íntima \\
Sofrimento no trabalho & Condições precárias de trabalho \\
& Relações de trabalho entre pares \\
& Endurecimento emocional \\
Estratégias defensivas & Negação do medo ou perigo \\
& Racionalização \\
\hline
\end{tabular}

subjetivas, condutas e ações dos trabalhadores, permitidas pelo arranjo laboral. Assim sendo, podemos considerar que tanto os modelos de organização do trabalho prescrito como as relações subjetivas dos trabalhadores com o trabalho têm papel fundamental na determinação de vivências de prazer (Mendes, 1995).

As agentes penitenciárias destacaram como aspectos que contribuem para o prazer no seu trabalho: gostar do que faz (tanto relacionado a uma conquista por ter sido aprovado em um concurso público e ter estabilidade, como pelo fato de poder visualizar que está cumprindo com suas obrigações), mesmo que o trabalho esteja associado a condições precárias; e o salário, que comparado a outros cargos públicos possui gratificações que agregam ao valor final. Por último, a escala de trabalho foi considerada "flexível" e, por isso, positiva por algumas das entrevistadas. "Eu sinto prazer no que faço, é uma conquista minha, fiz concurso e passei sozinha. Posso dizer que tenho orgulho de mim mesma e sou apaixonada pelo que faço" (ASP 1). "Eu gosto do que eu faço, por isso tu consegue trabalhar melhor, mesmo precário tu faz melhor teu trabalho, porque tu gosta" (ASP 4). “Quando nós fazemos uma revista e achamos algo escondido, seja com as presas ou no alojamento, isso mostra que cumprimos nosso trabalho" (ASP 2)".

A inexistência de melhores horizontes profissionais também foi apontada, tanto na escassez de programas de aperfeiçoamento e desenvolvimento profissional, bem como na ausência de um plano de carreira definido (Kurowski \& Moreno-Jiménez, 2002; Vasconcelos, 2000). No entanto, é compensada pelo salário que, embora não seja totalmente satisfatório, é apontado como razoável, sendo considerado um dos melhores dentro da carreira policial.

"O salário também poderia ser melhorado, mas por outro lado, se for comparado aí ao que se paga é satisfatório nesse aspecto, fazendo um parâmetro é" (ASP 8).

Outro fator assinalado como vantagem é a escala de serviço, permitindo trabalharem 24 horas e folgarem 72 . Isso proporciona aos agentes exercerem outras atividades nos dias de folga (até mesmo dentro do sistema penitenciário), os chamados "bicos", complementando a renda familiar.

"Uma coisa que considero boa é a escala de trabalho, tu trabalha um dia e folga três, pode ir no médico, fazer tuas coisas. O salário é bom, ao menos pra mim, eu considero bom" (ASP 1).

"A carga horária acho boa, comparando com outros serviços, tenho possibilidade de fazer diárias e aumentar um pouco a renda 
e, às vezes, acho que é mais seguro aqui do que lá fora" (ASP 3).

No entanto, há de se considerar que o trabalho também pode ser fonte de doença, risco e desprazer, o que revela o caráter ambíguo do mesmo. O sofrimento psíquico do profissional pode ser percebido quando o trabalho deixa de ser motivo de prazer, bem estar, satisfação, sentir-se útil, passando a ser lugar de dor, sofrimento e cansaço. A carga psíquica aumenta quando o trabalhador relata que não é valorizado, e faz seu trabalho de forma mecânica, ocorrendo um desgaste tanto físico como emocional. As condições de trabalho inadequadas prejudicam o bem estar e a satisfação no ambiente de trabalho (Dejours, 1992, 1994).

Nas condições materiais do trabalho, que englobam tarefas ditas de execução, o trabalhador se vê de algum modo impedido de fazer corretamente seu trabalho, constrangido por métodos e regulamentos incompatíveis entre si (Dejours, 1992). Prescrevese para o agente a função de garantir a guarda das Unidades e a vigilância permanente, no entanto, o efetivo cumprimento desta prescrição nem sempre é possível diante das condições reais de trabalho. As estratégias adotadas pelos agentes diante das adversidades podem, de alguma maneira, permitir a manutenção da funcionalidade das Unidades, mas podem também implicar importantes concessões quanto à natureza do trabalho e incremento das cargas psíquicas (Fernandes et al, 2002).

Como fator que contribui para o sofrimento no trabalho, as agentes penitenciárias mencionaram: a tarefa de ter que realizar a revista íntima, tanto nas presas como nas visitas dessas, atitude que causa constrangimento e humilhação na pessoa revistada. Esse mesmo fator já foi destacado em estudo anterior (Vasconcelos, 2000).
“A parte de fazer revista íntima é desagradável, seja nas presas ou nas visitas, é algo constrangedor pra elas e pra nós. Considero frustrante, porque falta condições de trabalho, se tivéssemos um raio-X facilitaria nosso trabalho, porque ao invés de fazer revista íntima, a presa passaria ali e deu. Às vezes, não funciona o detector de metais, aí temos que chegar mais perto, mas não podemos encostar nelas" (ASP 2).

Outro elemento de destaque - causador de sofrimento psíquico - foi as condições precárias de trabalho, tanto materiais (falta de recursos materiais e infraestrutura física) quanto humanas, pelo que são cobrados e responsabilizados caso não executem bem alguma atividade prescrita (sem terem apoio ou respaldo para tanto).

"Há falta de condições pra trabalhar, falta estrutura, falta viatura, porque a nossa vive quebrada. $O$ procedimento é exigido de um jeito, mas tem que fazer do jeito que dá e se dá errado, tu responde por isso" (ASP 3).

"Tem o sentimento de tu querer fazer mais e não ter condições pra isso. É a falta de condições pra trabalhar, as viaturas caindo aos pedaços, a falta de recursos, chega ao ponto de não termos folha de ofício pra trabalhar. Muitas vezes, comprarmos do nosso bolso pro trabalho não parar. Faço o melhor que posso, as condições são precárias, não é questão de não querer fazer, é não ter como fazer. Então, às vezes, é aquele se vira nos 30 . Vai muito da tua vontade de trabalhar, às vezes, pegamos ôni- bus pra ir na Susepe pois as viaturas estão estragadas, tiramos do nosso bolso pras coisas mais urgentes e as outras acabam ficando" (ASP 5).

"O agente meio que tem que fazer milagre. Então, muitas vezes, a gente faz coisas que não tem e a gente faz. Se der certo, bom, de ser errado, tu vai responder por dar errado. Se der errado tu vai responder por que não devia ter feito" (ASP 8).

Trabalhar não é apenas exercer atividades produtivas, mas também conviver. Assim, uma organização do trabalho racional deve antes de tudo preocupar-se com a eficácia técnica, mas deve também incorporar argumentos relativos à convivência, ao viver em comum, às regras de sociabilidade, ou seja, ao mundo social do trabalho, bem como argumentos relativos à proteção e realização do ego, ou seja, à saúde e ao mundo subjetivo (Dejours, 1999). Foi destacado que nem sempre existe boa convivência entre pares (colegas de trabalho). "E ainda tem os colegas que fazem fofoca, que querem te apunhalar" (ASP 6).

Chama muito a atenção o fato de não ter sido mencionado em nenhum momento nas entrevistas as dificuldades relativas à convivência com a população carcerária. Já que existem riscos de ataques violentos entre as próprias encarceradas e entre as encarceradas e as agentes penitenciárias, como alguns estudos anteriores apontam (Rumim, 2006; Vanconcelos, 2010). No entanto, essas questões podem não ter aparecido, devido às defesas utilizadas por essas profissionais para diminuir ou negar o risco a que estão expostas.

Segundo Dejours (1994), o sofrimento pode promover ideologias defensivas, suscitando assim uma ideologia defensiva, em que seu caráter é vital, fundamental e necessário. Sendo assim, o sofrimento pode aparecer por meio de ansiedade exagerada e, para evitá-la desenvolve-se um endurecimento emocional, o qual pode auxiliar a se envolver menos no trabalho, tornando-o menos sofrível, como apresenta as falas a seguir:

"Sentimento? Que que é isso? Com o tempo tu fica mais dura, não se emociona bem assim" (ASP 6).

"Com o tempo tu acaba ficando mais fria sentimentalmente, tu acostuma com as situações que acontecem" (ASP 4).

"No trabalho eu procuro ser bem profissional, estritamente profissional. Quanto menos sentimento existir melhor, tanto positivos quanto negativos, nem afetividade, nem ressentimento" (ASP 8).

As estratégias defensivas são mecanismos construídos individualmente ou coletivamente, nesse caso destacou-se entre elas: a negação e a racionalização da realidade, buscando recursos para lidar com uma condição de trabalho que faz sofrer. A racionalização compõe justificativas socialmente valorizadas para explicar situações desconfortáveis, desagradáveis e dolorosas que propiciam risco e impõem ritmo acelerado e/ou exigem elevados índices de desempenho e produtividade.

"Procuro fazer o que me cabe, não levando pra fora daqui os problemas aqui de dentro, assim como não trazendo os problemas lá de fora aqui pra dentro" (ASP 7).

Essas estratégias, fundamentadas na negação e na racionalização, consistem na minimização da percepção do que faz sofrer. Embora protejam contra os afetos dolorosos 
vindo das adversidades do trabalho, as estratégias defensivas podem operar como um sinal de alerta para a saúde psíquica dos sujeitos. A intensidade do uso das defesas pode levar ao seu fracasso, anestesiando o sofrimento vindo do ambiente laboral e, conseguintemente, levar ao adoecimento e a alienação (Barros \& Mendes, 2003; Dejours, 1997).

"Me preparo psicologicamente pra enfrentar o trabalho, sabendo que vai ser difícil. Quando venho pra cá, esqueço a família lá fora e quando saio daqui, esqueço aqui dentro. Às vezes, nem lembro que sou agente penitenciária" (ASP 6).

O reconhecimento surge como outro elemento fundamental para que o sofrimento no trabalho ganhe sentido e possa se transformar em prazer. Para Dejours (1997, 1999), o sentido do trabalho vincula-se ao estabelecimento de uma dinâmica de reconhecimento, que é condição indispensável no processo de mobilização subjetiva da inteligência e da personalidade no trabalho e se dá por duas vias de julgamento: o julgamento de utilidade e o julgamento de beleza. O primeiro diria respeito à utilidade técnica, social ou econômica dada à atividade singular desempenhada pelos trabalhadores. Quem estaria em condições de proferir esse julgamento seriam aqueles que, em relação ao sujeito, encontram-se em uma posição hierárquica superior, em que poderíamos entender como um julgamento vertical (Merlo, 2002). No entanto, as participantes mencionaram não se haver essa valorização por parte da instituição. $\mathrm{O}$ estudo de Lourenço (2010) apontou como uma queixa quem já está há mais tempo trabalhando no sistema prisional que os agentes nunca, ou quase nunca, são ouvidos sobre como a cadeia deveria funcionar, nem sobre o que deveria ser feito para que ela funcionasse melhor. Isso indica que não é valorizada, pela instituição, a inteligência prática ou o saber fazer dos agentes penitenciários, fatores essenciais na produção de saúde mental no trabalho (Dejours, 1997). "Não há reconhecimento. A Susepe não está nem aí pra nós" (ASP 2). "Não tem reconhecimento na Susepe" (ASP 3).

O julgamento de beleza é aquele efetuado pelos pares, ou seja, aqueles que, situados na mesma faixa hierárquica e compartilhando o mesmo ofício, estão em condições de avaliar a singularidade e a beleza do trabalho executado, ao qual poderíamos entender como um julgamento horizontal. Importante ressaltar que o julgamento deve referir-se ao trabalho e não à pessoa, para permitir a construção da identidade. (Merlo, 2002). Embora faça parte das expectativas de todos trabalhadores, o reconhecimento raramente é conferido de modo satisfatório. "Por horas, até que tu é reconhecida, tem gente que sabe que a gente trabalha, que faz tudo corretamente" (ASP 6). "Acho que o trabalho é reconhecido por alguns, mas não se pode agradar a todos" (ASP 7).

A Organização do Trabalho é constituída pelos elementos prescritos (formal ou informalmente), que expressam as concepções e as práticas de gestão de pessoas e do trabalho presentes no locus de produção e balizam o seu funcionamento. As condições de trabalho são constituídas pelos elementos estruturais presentes no locus de produção e caracterizam sua infraestrutura, apoio e práticas administrativas. As relações de trabalho são constituídas pelos elementos interacionais, que expressam as relações socioprofissionais de trabalho, presentes no locus de produção e caracterizam sua dimensão social
(Ferreira \& Mendes, 2003).

$\mathrm{O}$ agente da segurança penitenciária, sem recursos materiais disponíveis e tendo que conviver com o modo degradado de funcionamento da prisão, utiliza como saída para a falta de racionalidade do trabalho a intuição e a experiência acumulada, implementando arranjos e improvisações para realizar o serviço. Essas soluções, realizadas na base do improviso, acabam por gerar o medo, que leva igualmente à violência, formando um círculo vicioso que se instala, num universo brutal e impiedoso. Tal situação castiga, sobretudo, a saúde do agente, vítima das cargas pesadas decorrentes do trabalho precário (Vasconcelos, 2000).

As deficiências de recursos disponíveis, muitas vezes por não serem de conhecimento da população, geram nela descontentamento e incompreensão. Recursos humanos e materiais são peças essenciais no contexto do trabalho, e a sua escassez pode prejudicar o desenvolvimento das tarefas a serem executadas (Camelo \& Angerami, 2008). A precarização das condições de trabalho traz consequências nocivas para a saúde do trabalhador (J. B. Ferreira, 2009; Mendes 2007). Nesse estudo, verificou-se que as condições de trabalho não são favoráveis, tanto em termos físicos quanto de equipamentos, observou-se a falta de materiais para trabalhar, baixo número de funcionários, más condições das viaturas, falta de cursos de capacitação.

Como se pode constatar, o trabalho do agente é permeado por contradições. Ao mesmo tempo em que a escala de trabalho se destaca como atrativo em termos de ganhos monetários, ao propiciar a chance de ter outra fonte de renda, a relação custo/ benefício desse ganho contabiliza perdas valiosas na qualidade de vida do agente. O salário é apontado como razoável; no entanto, a necessidade, relatada por alguns, de realizar um trabalho extra indica que o mesmo pode ser insuficiente e traz como contrapartida muitas queixas dessa sobrecarga.

\begin{abstract}
"E outra coisa seria acabar com as horas extras, mas pra isso precisava oferecer um salário melhor, porque tem gente que saí de um lugar e vai pra outro, imagina isso anos a fio, a pessoa não descansa, acaba agindo como os presos, acaba ficando louco. Mas tem gente que já incorporou essas horas extras como salário, não vai ser fácil deixar, então teria que ter um posicionamento firme da Susepe" (ASP 5).
\end{abstract}

Ainda sobre a escala de trabalho, é possível a dupla carga horária no Rio Grande do Sul. Nesse sentido, o agente penitenciário pode cumprir a carga horária de 24/24 horas. Três entrevistadas estavam trabalhando no regime de Quinzena (como elas denominam), em que trabalham os primeiros 15 dias do mês no local em que são lotadas (por lotação, entende-se a unidade específica do sistema prisional, na qual o servidor está vinculado) e nos outros 15, fazem diária em outro estabelecimento penal, trabalhando em um dia e folgando no outro. Dessa forma, há um aumento substancial da renda, bem como uma exposição duplicada aos fatores de risco (Santos, 2010).

Essas condições agravam o sofrimento, dificultam sua transformação e abrem caminho para as novas patologias do trabalho. Entre elas, destaca-se a patologia da sobrecarga, que decorre de uma carga de trabalho que extrapola a capacidade das pessoas; relaciona-se à intensificação do trabalho, sendo 
reforçada pela ideologia da excelência (Dejours, 2007; Mendes, 2007).

Cabe salientar ainda que as participantes da pesquisa foram todas do gênero feminino, o que pode ter influenciado nos resultados obtidos. Estudo anterior (Fernandes et al, 2002) destacou que as mulheres apontam mais estresse associado a este tipo de trabalho do que os homens, provavelmente por razões culturais, de serem mais vulneráveis a tensões no trabalho, com menos recursos físicos de reagir a essa violência e com maior dificuldade de se impor como autoridade.

Conclui-se que a vivência de sofrimento no trabalho está relacionada ao contexto de trabalho (organização, condições e relações de trabalho), no qual as atividades são realizadas. Especificamente, o sofrimento instala-se a partir do momento no qual os trabalhadores tornam-se impossibilitados de sentir prazer de forma direta e/ou de utilizar o processo de mobilização coletiva (modos de agir coletivo dos trabalhadores, viabilizados no espaço público de discussão e na cooperação), em função das restrições do contexto no qual o trabalho é desenvolvido, restando-lhe o uso das defesas, que podem servir de proteção e, ao mesmo tempo, levar a uma espécie de alienação (Dejours, 1994, 2007; Ferreira \& Mendes, 2003).

\section{Considerações finais}

Quanto aos resultados finais da pesquisa, destaca-se que a exigência que a função de agente penitenciária impõe aos trabalhadores, sem a contrapartida de um apoio ou de condições de trabalho favoráveis, gera situações que podem levar essas trabalhadoras ao sofrimento psíquico. Alguns fatores foram identificados, tais como: a desmotivação e o sentimento de impotência pelas condições inadequadas de trabalho, a falta de reconhecimento e a qualidade de vida precária, estes fatores são considerados altamente prejudiciais, influenciando o comportamento do indivíduo, tornando-o mais fadigado, com poucas perspectivas sobre o futuro, frustrado, ansioso.

Os achados demonstram vivências de prazer pelo que lhes é oferecido em termos salariais e de estabilidade no emprego, no entanto esses elementos não são suficientes para garantir a saúde mental, diante de tanta precariedade das condições de trabalho, como elemento provocador de sofrimento. Diante dessas questões, as estratégias defensivas que mais se evidenciaram foram negação e racionalização, procurando amenizar um pouco de uma realidade tão nociva à saúde. Conclui-se que os profissionais que participaram do estudo tentam encontrar caminhos para a manutenção da saúde, ao utilizarem mecanismos que favorecem o enfrentamento do sofrimento e a busca do prazer. Mas esses caminhos não garantem que elas estejam conseguindo se manter bem, pois eles têm um custo e não modificam as condições deletérias de trabalho.

Nota-se também a carência de serviços de atenção à saúde, capazes de prevenir ou minimizar o sofrimento desse grupo de trabalhadoras. Acredita-se que, em virtude dessas situações, compete à administração penitenciária a organização de um Serviço de Assistência Psicológica exclusiva para esses trabalhadores, oferecendo espaço para acolher o sofrimento (quando houver) proveniente das práticas profissionais, pois nessa pesquisa apareceram alguns fatores consideráveis de sofrimento, sobretudo relacionado às condições precárias de trabalho e as cobranças sem apoio ou respaldo da instituição. Ressaltados no relato de uma participante: "Faço o melhor que posso, as condições são precárias, não é questão de não querer fazer, é não ter como fazer". Assim, tornam-se necessárias políticas públicas de valorização e qualificação profissional voltada para o agente penitenciário. Ressalta-se que o número de participantes é pequeno para fazer generalizações ou conclusões quanto à dialética do prazer - sofrimento no trabalho penitenciário. Por isso, sugere-se ampliar as pesquisas com esse grupo, buscando dar maior voz e visibilidade a esses trabalhadores.

\section{Referências}

Almeida, L. L., \& Merlo, A. R. C. (2008). Manda quem pode, obedece quem tem juízo: Prazer e sofrimento psíquico em cargos de gerência. Cadernos de Psicologia Social do Trabalho, 11(22), 139-157.

Bardin, L. (1994). Análise de conteúdo. Lisboa: Edições Setenta.

Barros, P. C. R., \& Mendes, A. M. B. (2003). Sofrimento psíquico no trabalho e estratégias defensivas dos operários terceirizados da construção civil. Psico USF, 8(1), 63-70. Recuperado de http://dx.doi.org/10.1590/S141382712003000100009

Conselho Federal de Psicologia. (2000). Resolução 016/2000: Diretrizes e normas regulamentadoras de pesquisas em Psicologia com seres humanos. Brasília: CFP.

Camelo, S. H. H., \& Angerami, E. L. S. (2008). Riscos psicossociais no trabalho e estresse. Ciência, Cuidado e Saúde, 7(2), 232-240.

Centurião, L. R. M. (1990). O agente penitenciário e seu contexto. Revista da Escola do

Serviço Penitenciário, 1(3), 45-52.

Cooper, C. L. (1997). The experience of work-related stress across occupations. Journal of Managerial Psychology, 20(2), 178-187.

Correia, A. P. (2006). Uma análise dos fatores de risco da profissão do agente penitenciário: Contribuições para uma política de segurança e saúde na gestão penitenciária. (Monografia). Recuperado de http://www.depen.pr.gov. br/arquivos/File/ADEMILDO_\%20PASSOS_CORREIA2006.pdf Dejours, C. (1992). A loucura do trabalho: Estudo de psicopatologia do trabalho. (5 ed.). São Paulo: Cortez-Oboré.

Dejours, C. (1994). Trabalho e saúde mental: Da pesquisa à ação. In C. Dejours, E. Abdoucheli \& C. Jayet (Orgs.), Psicodinâmica do trabalho: Contribuições da escola dejouriana à análise da relação prazer, sofrimento e trabalho. São Paulo: Atlas.

Dejours, C. (1997). O fator humano. Rio de Janeiro: Fundação Getúlio Vargas.

Dejours, C. (1999). A banalização da injustiça social. Rio de Janeiro: Fundação Getúlio Vargas.

Dejours, C. (2004). Prefácio. In S. Lancman \& L. I. Sznelwar (Orgs.), Christophe Dejours: Da psicopatologia à psicodinâmica do trabalho. Rio de Janeiro: Fiocruz, Brasília: Paralelo 15.

Dejours, C. (2007). A psicodinâmica do trabalho na pós-modernidade. In A. M. Mendes, S. C. Cruz Lima \& E. Facas (Orgs.), Diálogos em psicodinâmica do trabalho. Brasília: Paralelo15.

Dejours, C. (2010). Suicídio no trabalho: O que fazer? Brasília: Paralelo 15.

Denzin, N. K., \& Lincoln, Y. S. (1994). Manual de pesquisa qualitativa. Thousand Oaks: Sage Publications.

Departamento Penitenciário Nacional (DEPEN). (2006). Recuperado de http:// www.pr.gov.br/depen/dp_quem.shtml

Eccel, C. S., Grisci, C. L. I., \& Tonon, L. (2010). Representações do corpo em uma revista de negócios. Psicologia \& Sociedade, 22(2), 309-317.

Fernandes, R. C. P., Silvany Neto, A. M., Sena, G. M., Leal, A. S., Carneiro, C. A. P., \& Costa, F. P. M. (2002). Trabalho e cárcere: um estudo com os agentes 
penitenciários da região metropolitana de Salvador, Brasil. Cadernos de Saúde Pública, 18(3), 807-816.

Ferreira, J. B. (2009). Perdi um jeito de sorri que eu tinha: Violência, assédio moral e servidão voluntária no trabalho. Rio de Janeiro: 7 Letras.

Ferreira, M. C. (2004). Bem-estar: Equilíbrio entre a cultura do trabalho prescrito e a cultura do trabalho real. In A. Tamayo (Org.), Cultura e saúde nas organizações. Porto Alegre: Artmed.

Ferreira, M. C., \& Mendes, A. M. (2003). Trabalho e riscos de adoecimento: $O$ caso dos auditores-fiscais da previdência social brasileira. Brasília: Edições LPA, Fenafisp.

Flach, L., Grisci, C. L. I., Silva, F. M., \& Manfredini, V. (2009). Sofrimento psíquico no trabalho contemporâneo: Analisando uma revista de negócios. Psicologia \& Sociedade, 21(2), 193-202.

Gil, A. C. (1995). Métodos e técnicas de pesquisa social. São Paulo: Atlas.

Grisci, C. L. I. (1999). Trabalho, tempo e subjetividade: impactos da reestruturação produtiva e o papel da psicologia nas organizações. Psicologia: Ciência \& Profissão, 19(1), 2-13.

Heloani, R., \& Lancman, S. (2004). Psicodinâmica do trabalho: O método clínico de intervenção e investigação. Produção, 14(3).

Kurowski, C. M., \& Moreno-Jiménez, B. (2002). A Síndrome de Burnout em funcionários de Instituições penitenciárias. In A. M. T. Benevides-Pereira (Org.), Burnout: Quando o trabalho ameaça o bem-estar do trabalhador. São Paulo: Casa do Psicólogo.

Lancman, S., \& Jardim, T.A. (2004). O impacto da organização do trabalho na saúde mental: um estudo em psicodinâmica do trabalho. Revista de Terapia Ocupacional da Universidade de São Paulo, 15(2), 84-96.

Laurrel, A. C., \& Noriega, M. (1989). Processo de produção e saúde: Trabalho e desgaste operário. São Paulo: Hucitec.

Lei $\mathrm{n}^{\circ}$ 9.228, de 01 de fevereiro de 1991 (1991, 01 de fevereiro). Dispõe sobre a criação do quadro especial de servidores penitenciários do Estado do Rio Grande do Sul e dá outras providências. Recuperado de http://www.al.rs. gov.br/legiscomp/arquivo.asp?Rotulo=Lei $\mathrm{n}^{\circ}$ 9228\&idNorma $=500 \&$ tipo $=$ pdf

Lourenço, L. C. (2010). Batendo a tranca: Impactos do encarceramento em agentes penitenciários da região metropolitana de Belo Horizonte. Dilemas, $3(10), 11-31$.

Ministério da Justiça (2011). Conselho Nacional de Politica Criminal e Penitenciária. Regras mínimas para o tratamento de presos no Brasil. Recuperado de http://www.mj.gov.br/cnpcp/resolucoes/res1994_11_11_n14. htm

Mendes, A. M. (1995). Aspectos psicodinâmicos da relação homem-trabalho: As contribuições de C. Dejours. Psicologia: Ciência e Profissão, 15(1-3), 34-38.
Mendes, A. M. (1999). Valores e vivências de prazer-sofrimento no contexto organizacional. (Tese de Doutorado não publicada). Universidade de Brasília, Brasília.

Mendes, A. M. (2004). Cultura organizacional, prazer e sofrimento no trabalho: uma abordagem psicodinâmica. In: A. Tamayo (Org.), Cultura e saúde nas organizações. Porto Alegre: Artmed.

Mendes, A. M. (2007). Da psicodinâmica à psicopatologia do trabalho. In A. M. Mendes (Org.), Psicodinâmica do Trabalho: Teoria, Método, Pesquisas. São Paulo: Casa do Psicólogo.

Mendes, A. M., \& Araújo, L. K. R. (2011). Clínica Psicodinâmica do Trabalho: Práticas Brasileiras. Brasília: Ex Libris.

Mendes, A. M., Borges, L. O., \& Ferreira, M. C. (2002). Trabalho em transição, saúde em risco. Brasília: Universidade de Brasília.

Merlo, A. R. C. (2002). Psicodinâmica do trabalho. In M. G. Jacques \& W. Codo (Orgs.), Saúde Mental \& Trabalho-Leituras. Petrópolis: Vozes.

Minayo, M. C. S. (1994). Ciência, técnica e arte: O desafio da pesquisa qualitativa. In: M. C. S. Minayo (Org.), Pesquisa Social: Teoria, Método, Criatividade. ( $21^{\mathrm{a}}$ ed) (pp. 9-29) Petrópolis: Vozes.

Rio Grande do Sul. (2006). Secretaria da Justiça e da Segurança. Superintendência dos Serviços Penitenciários. Departamento de Tratamento Penal. Divisão de Trabalho. [Dados do Sistema Prisional do RS]. Recuperado de http://www. susepe.rs.gov.br/conteudo.php?cod_menu=77\&cod_conteudo $=275$

Rumin, C. R. (2006). Sofrimento na vigilância prisional: O trabalho e a atenção em saúde mental. Psicologia, Ciência e Profissão, 26(4), 570-581.

Santos, M. M. (2010). Agente penitenciário: Trabalho no cárcere. (Dissertação de Mestrado). Universidade Federal do Rio Grande do Norte, Natal. Recuperado de http://bdtd.bczm.ufrn.br//tde_busca/arquivo.php?codArquivo=3869

Sistema Integrado de Informações Penitenciárias. (2007). Recuperado de http:// portal.mj.gov.br/data/Pages/MJD574E9CEITEMID598A21D892E444B59 43A0AEE5DB94226PTBRIE.htm

Superintendência de Serviços Penitenciários (SUSEPE). (2006). Edital de Concurso $N^{\circ}$ 01/2006-SUSEPE. Recuperado de http://www.susepe.rs.gov. br/upload/1317931655_Edita1012006AberturaConcursoAPeASP2006.pdf

Taets, A. R. F. (2009). Agente penitenciária: Uma vigia de fronteiras. Trabalho proposto para apresentação no I Encontro Nacional de Antropologia do Direito na Universidade de São Paulo.

Vasconcelos, A. S. F. (2000). A saúde sob custódia: um estudo sobre agentes da segurança penitenciária no Rio de Janeiro. (Dissertação de Mestrado). Fundação Oswaldo Cruz, Rio de Janeiro. Recuperado de http://arca.icict. fiocruz.br/handle/icict/5181

Rubia Minuzzi Tschiedel,mestre em Psicologia Clínica pela Universidade do Vale do Rio dos Sinos (UNISINOS), é Técnica Superior Penitenciária na Superintendência dos Serviços Penitenciários (SUSEPE). Endereço para correspondência: Avenida França, 841, apto 301, bairro Bela Vista, CEP: 95076-000 - Caxias do Sul/RS. Telefones: (54) 3290-4310 e (51) 9786-5696. Email: rubia_tschiedel@yahoo.com.br Janine Kieling Monteiro, doutora em Psicologia pela Universidade Federal do Rio Grande do Sul (UFRGS), é professora do Programa de Pós-Graduação em Psicologia da Universidade do Vale do Rio dos Sinos (UNISINOS). Email: janinekm@unisinos.br 